\title{
On Intercultural Communicative Competence: Student-teachers' Accounts of Colombian Cultural Identity
}

\author{
Francisco Perez-Gomez ${ }^{1}$ \& Dra. Dina Elizabeth Cortes Coss ${ }^{2}$ \\ ${ }^{1}$ Languages Department, Universidad Pedagógica Nacional, Colombia \\ ${ }^{2}$ Posgraduate Department, Universidad Internacional Iberoamericana, Mexico \\ Correspondence: Francisco Perez-Gomez, Language Department, Universidad Pedagógica Nacional, Colombia.
}

Received: October 27, 2021

Accepted: November 15, 2021

Online Published: November 23, 2021

doi: $10.5539 /$ elt.v14n12p69

URL: https://doi.org/10.5539/elt.v14n12p69

\begin{abstract}
In student-teachers' education, it is fundamental to foster the intercultural communicative competence for them to express their views on cultural concepts and phenomena in written and orally, with native and non-native speakers of a foreign language. In the same vein, future foreign language teachers, particularly at an early stage of their learning process, are expected to possess some basic citizen competencies which allow them, amongst other things, to show an understanding of the country they live in, the cultural diversity it has, and the current situation they and their co-nationals are facing (cognitive dimension).

Bering in mind the importance of competences mentioned before. This short-scale quantitative study set out to classify the perceptions that a group of student-teachers had on Colombia, their cultural identity, and Colombians' cultural identity in general. To that end, one oral and two written short narratives along with a final questionnaire were collected and analysed using Atlas TI. 8 and Excell spreadsheets. The counting and classification of prominent speech parts that conveyed perceptions (nouns, nouns plus adjectives and adjective per se) unveiled that participants held quite optimistic views on their nation, particularly in cultural, natural, geographic, and culinary aspects. It was also revealed that student-teachers had a high appreciation of themselves culturally speaking, praising their personality and mood as most important features. Furthermore, it was unveiled that participants held a positive view about their compatriots, highlighting their personality, mood, and character. It is important to remark that positive views about own identity were much higher than general views on Colombians.
\end{abstract}

Keywords: cultural identity, intercultural communicative competence, views on Colombia, views on Colombians, narratives, discourse, citizenship competence

\section{Introduction}

21 st century skills for future foreign language teachers have become a pressing need of language teaching programmes and administrators to train student-teachers in competences which surpass the mere command of linguistics skills. Future language teachers ought to show a high level of competences when it comes to communicating in different contexts, with different speakers, and about different topics in English as well as display a firm grasp of the current reality of their country, their surroundings and their co-nationals while talking and writing in that target language. Through a direct observation, in-situ experience and the results obtained in an exploratory questionnaire, we could find that despite the new curriculum of the English Language programme at a Colombian public university states expressly that prospective teachers shall possess a standard level of performance in intercultural and diverse contexts while expressing views and perspectives about cultural phenomena and concepts in L2, participants in this study have been mostly mostly exposed to linguistic content and language-oriented activities, developing speaking, writing, listening, and reading skill instead of developing as well other relevant competences that they require to perform suitably as educators in the current Colombian educational setting.

One of the cultural phenomena that English student-teachers in said context are supposed to embrace, comprehend, and interpret in initial levels is their cultural identity, as the ground to understand the way other cultures and realities are set. As this expectation has not been fully met in the language and culture courses they have been taught so far due to national strikes, local strikes, the pandemic and remote education drawbacks, we 
deem highly relevant to approach the cultural views that a group of 15 young Colombian student-teachers hold on Colombia, themselves, and their co-nationals.

Studies revolving around national identity and the development of communicative intercultural competences in prospective teachers do not abound at a national level, least of all in the local context. Yet, there are some appealing investigations carried out in different educational scenarios that are worth being mentioned in the national milieu, as the one conducted by Motta (2015), where highly constituent elements of Colombian cultural heritage were explored and analysed; the one led by Bedoya et al. (2015), where some didactic units were tailored to enrich highschoolers' cultural knowledge about Colombia; the critical discourse analysis research of National Geographic done by Pérez-Marín (2017), in which Colombian identity was associated with negative aspects such as weak governments, poverty and Colombian dependance upon powerful nations such as the U.S.A; the comparative study conducted by Beltrán (2015), which inquired into the perceptions of some student-teachers from a Colombian and a Chilean university about source culture topic, which encouraged them to learn English, and the investigation done by Beltrán and Vela (2017), which sought to enhance English prospective educators' teaching skills to incorporate local culture elements in L2 lessons through artistic manifestations, valuing and understanding cultural diversity.

On the global arena, cultural identity has been connected to cultural negotiations programmes as in Meihani and Salite's research (2019), which attempted to decipher perspectives of English students about their teacher's including intercultural problematics in the classroom, and those educator's developing their own identification; it has been also linked to the belief of learners developing two identities while studying a foreign language as in the qualitative study led by Gholaminejad (2017), which was aimed to identify if a group of undergraduate students experienced reverse conceptual transfer in their English classes. Furthermore, it has been related to multicultural elements as in the short-scale qualitative research done by Oprescu (2016), which looked to identify aspects that entailed cultural identification, namely intercultural communication and awareness, and it has been framed within cultural diversity scenarios, as it is the case of the qualitative study case conducted by Vélez (2019), which was intended to dig into social sciences curricula, inquiring into the potential cultural development and enrichment enacted by the content and contextualised activities suggested by teachers.

Most of the studies revisited in the literature suggest the notion of cultural identity as a concept which embodies positive aspects connected to belonginess, identification with a particular group or nation, and to categories such as nationality, ethnicity, race, gender, and religion as Chen (2014) pinpoints. This idealisation of identity tends to be monolithic and already finished; everything that does not fall in the previous categories is conceived of as different and referred to global or national terms labelled by abstract nouns as heritage, development, community, society, nation, union, agreement, covenant, etc. to be understood, and therefore, accepted.

This study deviates from the views above in that we do not perceive identity as being permanently positive or negative or as a goal that is reached, or a state which is achieved. Conversely, we share the views of Bhabha (1994) to whom identity refers to a process in which we constantly face an otherness that questions us and makes us reformulate what we think defines us. Accordingly, identification is not precisely defined by an affirmation or reaffirmation of a given identity, but by the transformation the cultural subjects experience when they adopt an image of that identity, which is projected toward the otherness. In harmony with these thoughts, we share an understanding with Hall and Du Gay's views (1996) for whom identity is unfinished and is always being modified and transformed, according to the historical moment, circumstances and mainly, the discourses the subjects have constructed and reconstructed from their interactions with others. Consequently, we also agree with the idea that the pursuit of identity (identification) as a constant process embodies a meaning practice where people move across a world of differentiation, not only in relation to the others but with themselves. In such a differentiation, Hall and Du Gay suggest, subjects use strategies to position themselves, construct and reconstruct themselves as cultural agents.

Within these theoretical foundations, as student-teachers' educators and researchers, we place the urgent need of gaining insights into the views that a group of prospective teachers hold regarding what they consider their cultural identity is, and quite importantly, the need that they have to develop their intercultural communicative competence. With that aim in mind, we prioritise the following question as our guiding research inquiry: What are the commonest cultural perceptions that a group of English student-teachers might hold about their country, their identity and Colombians' identity in general? The aim that we traced as general in our study is consequently, to classify the concepts and attributes that a group of English student-teachers might assign to their country, their identity and Colombians' identity in general. 
We are aware of the fact that developing intercultural communicative competence in student-teachers is a complex and long-term goal, which cannot be fully achieved in a single course. Bearing this in mind, we share the view that in principle, there is a fundamental stage in which the teaching of intercultural skills implies the implementation of activities revolving around knowledge, reflection, and interpretation of local culture in order to comprehend own context and reality, which in the long run will be the foundation to understand other cultures and their people as well as interact with them (Byram, 1997; Areizaga, 2001; Aguaded, 2006; Chen, 2020) and to interpret other cultural contexts and the reality of people there, which is interestingly and directly connected to the cognitive domain of the citizenship competence.

In this short-scale quantitative study the perceptions on three variables (views on Colombia, views on own identity and views on Colombians) will be measured firstly, by counting and classifying some speech parts as nouns, nouns plus adjectives and adjectives into positives and negatives, and on a second level by assigning codes to those speech parts depending upon the aspects they represent in the narrative. From the knowledge we have on the local and national contexts as well as participants, we venture to hypothesise that the views future teachers have on their country will be mostly positive, as they tend to be patriotic; secondly, that the views they have on themselves culturally speaking will tend to be positive because customarily, subjects do not want to lose their image or face while sharing those perspectives and thirdly, the views they have on Colombians' identity will not be as positive as the ones they have about themselves, as individuals tend to be more judgmental and critical of others when issuing an opinion, and they prefer to expose others rather than being exposed.

\section{Method}

This short scale action-research study was conducted under the quantitative paradigm. Two main collection tools were used: written and oral narratives and a questionnaire. The variables considered here were views on Colombia, views on own identity, and views on Colombians. Following Miles et al.'s suggestions about deductive coding (2014), as cited in Burkholder (2019), we used predermined labels to name the variables, based upon the literature review we had conducted, the theoretical framework we had constructed as well as the knowledge we had accrued about the subject matter.

Three narratives were designed using a guided format, and they were elaborated in such an inductive way that they allowed researchers to retrieve information about the variables implied in the study. The first two narratives were expected to be made by students in written and uploaded on the platform provided for that end, and the third one was supposed to be recorded and sent by WhatsApp or uploaded on the said platform. All fifteen participants elaborated their narratives as instructed. Thus, fourty-five narratives were considered in this study.

The questionnaire was designed taking into account each of the variables mentioned previously. It contained six closed-ended questions designed with the purpose of verifying and gaining further quantitative insights about initial coding emerged from narratives. In first question, participants were asked to give a precise account on the level of perception, being negative or positive, which they had about their country. In second question, they were asked to provide a precise account for the level of perception, either positive or negative about themselves as Colombians, and in the third, they were expected to do the same but with their perception about Colombians in general. In fourth question, they were required to choose the negative and positive aspects they associated with their country. In fifth question, they were prompted to choose from a list the negative and positive attributes they found in themselves as Colombians and finally, in sixth question, they were instructed to choose from a list of options, the negative and positive attributes which they perceived about their co-nationals.

\subsection{Variables}

The variable views on Colombia refers to all nominalisations and attributes that participants mention in the written and oral narratives regarding their country. It was measured nominally by classifying nouns into positive and negative (for example: peace/violence), and by assorting the collocation adjective plus noun into positive and negative (for example, polite people/rude people). Then, the positive and negative codes obtained were labelled depending on the elements they referred to, for instance the noun poverty is negative and belongs to the label economic aspects. Both coding stages were done in Atlas TI. 8. The results obtained for this variable were checked progressively and reported completely through cross tabulation designed in Excel.

The variable views on own identity is connected to all attributes and traits that student-teachers assign to themselves in the narratives while they try to define themselves as Colombians. It was measured nominally through the classification of adjectives into positive and negatives (v.g kind/impolite). Afterwards, the negative and positive adjectives counted so far were ranked into four labels: appearance adjectives, personality adjectives, mood adjectives and character adjectives. The two levels of coding were done in Atlas TI.8, and the frequency of the adjectives used in the narratives was shown in a cross tabulation designed in Excel. 
Finally, the third category view on Colombians refers to the attributes or characteristics participants assign to their co-nationals in general in the narratives. The process followed to measure the second variable (views on own identity) was adopted for the third variable. That is to say, adjectives were ranked into positive and negative and subsequently, were assigned a second label depending on the aspects they made reference to (cultural, political, economic, social aspect etc). These coding stages were done in Atlas Ti 8 as well and as final step, a cross tabulation on Excel was used to report the frequency of adjectives in the narratives. To verify the initial results obtained through the coding and in the cross tabulation, participants were administered a questionnaire, which also served to make a contrast between findings in the first stage and findings in the second phase.

\subsection{Sampling Procedures and Participants' Characteristics}

Participants in this study were fifteen student-teachers from an English as a Foreign Language Department teaching programme at a Colombian public university. Convenience sampling was used to choose them. To be selected, they should be taking their second semester, and be part of the second cohort of the New Curriculum from the above-mentioned language department. This cohort represented particularly the First Cycle of Study, in which deep culture topics, critical thinking, and intercultural issues must be a priority. The total number of students meeting the requirements and whom were contacted was twenty. In the end, fifteen student-teachers decided to take part in the research freely ( $75 \%$ of potential population).

Based on the preliminary information gathered about participants, it can be said that $60 \%$ of them reported being females, and $40 \%$ males. Their age ranged from 16 to $24.90 \%$ of them manifested they had not had any experience studying or discussing upon Colombian cultural identity in their academic life, whereas the reamaining $10 \%$ expressed that they had studied some things related to national identity. Regarding their cultural experiences inside Colombia, $85 \%$ of respondents indicated that they had only visited famous and touristic places all around the country, while the $15 \%$ stated they had visited both, touristic as well as remote and not so popular places. This means that most participants had experienced the mainstream Colombia when it comes to the spots that are advertised on mass media and by government-sponsored marketing campaigns, and that just a minority had the opportunity to see both sides of the country, the one to be displayed and the one which has been historically neglected and abandoned by the government. Concerning cultural experiences lived abroad, $20 \%$ of participants expressed they had been to other countries, whereas the $80 \%$ of them answered that they had never travelled or lived abroad. This means that most of participants had not had direct contact with other cultures until that moment, whereas a minority had at least travelled and experienced other cultures in person.

\subsection{Research Design}

Considering the pandemic and all the circumstances this phenomenon has brought about, we decided to carry out this eight-month quantitative action-research study in a remote environment by combining the use of a platform like TEAMS (synchronous sessions) with the use of Whatsapp and institution e-mail for the asynchronous sessions. A group under the title Colombian Cultural identity was created in TEAMS, and participants were added. Most of the oral narratives were collected in synchronous fashion, which means that the students connected to the session opened by the researchers, and that their improvised narratives were recorded. As they shared those narratives, their peers listened carefully and made comments about the content. Few of the oral narratives were shared by participants in an asynchronous fashion, that is to say, they did not connect to the sessions opened by reseaerchers, instead they uploaded them on Teams in the assignment entry created for that purpose, used Whatsapp or their email to upload them Teams when they felt ready to do it. The majority of the written narratives were shared by participants in asynchronous fashion in TEAMS and via e-mail. Few students got connected on TEAMS to prepare and share these written narratives with researchers in a remote and synchronous manner. As for the questionnaire, it is important to say that a Google form was created, and all participants answered it in asynchronous fashion. At the end of the process, researchers sent over the written narratives as well as the transcription of the oral ones to socialise their content.

\section{Results}

Let us remember that data collection instruments were written and oral narratives as well as a questionnaire. The answers obtained in the questionnaire allowed cross-examining and validating information obtained through the narratives in the two coding phases carried out in the software Atlas TI. 8. Temporary and final number of codes obtained were depicted in Excel crossed-tabulation charts.

\subsection{Results from First Written Narratives}

In first written narratives, participants were requested to write an 80-100-word text in which they expressed their views, feelings, and opinions on Colombia. The variable being measured here was labelled Views on Colombia, 
and the unit of analysis were on the one hand, the nouns which participants used to refer to their country and on the other hand, the collocations adjective plus noun they made use of to describe their nation.

\subsubsection{First Coding Phase Results}

The first coding phase was conducted by classifying all nouns and adjective-nouns collocations into negative and positive, according to the context in which they appeared, and the interpretation researchers made about the way they were used in the narratives.

Table 1. First coding phase: Views on Colombia

\begin{tabular}{lllll}
\hline positive nouns & negative nouns & $\begin{array}{l}\text { positive adjective-noun } \\
\text { collocations }\end{array}$ & $\begin{array}{l}\text { negative adjective-noun } \\
\text { collocations }\end{array}$ & total \\
\hline 105 & 92 & 93 & 14 & 254 \\
\hline
\end{tabular}

As it can be seen in Table 1, the codes named positive nouns represent the most frequent views first narratives reveal about the perception participants have about their country, with a $41.33 \%$ of the total number of codes obtained in the counting. The codes labelled positive adjective-noun collocations account for the second most frequent views about Colombia, with a $36.61 \%$ of total number of codes. The codes called negative nouns rank third in terms of most frequent views participants hold about their nation, with a $16.53 \%$ of the 254 codes found. The codes entitled negative adjective-noun collocations represent the least frequent views student-teachers have about their country.

If the codes positive nouns and positive adjective-noun collocations are added, we obtain 198 codes (77.95\%), and if the labels negative nouns and negative adjective-noun collocations are added, we obtain 56 codes (22.04\%), which reveals two important facts. Firstly, positive codes outnumber the negative ones by almost 56\% and secondly, the first narratives unveil that the views participants have about their country tends to be highly positive. In terms of ratio, this means that for every negative code narratives contain, participants use approximately 3.5 positive codes.

\subsubsection{Most Frequent Words Found in the First Coding Phase}

Upon careful analysis of the codes found in the first stage, we see that within the label positive nouns the commonest terms used by participants were:

Beauty (mentioned three times in the narratives)

--> "it is not a secret how expensive it could be for a native person to travel around and get to enjoy the beauty of the country..." (7th narrative, line 2)

--> "There are unique landscapes, where you can see the beauty of this country". (8th narrative, line 3)

--> "Colombia is synonym for beauty, in every corner of this country resides a living story of our ancestors, a story of love, freedom, courage, combat, and belief". (13th narrative, line 3)

Ajiaco (typical chicken and potatoes soup /mentioned twice)

--> "Even though she could taste typical dishes such as ajiaco, changua, chocolate with cheese, and empanada for the first three days, she was stolen by a gang of black vultures on the fourth day". (2nd narrative, line 10)

--> "food is varied and exquisite, for example, Ajiaco, Mondongo...". (6th narrative, line 4)

Plains (mentioned four times)

--> "Therefore, she decided to move to the Orinoco plains". (2nd narrative, line 14)

--> "In Colombia you can find magical places, tropical paradises, crystalline seas and rivers, great plains and exotic animals". (3rd narrative, line 3)

--> "There are many kind persons with a huge capacity to give love to others and passionate about the plains". (12th narrative, line 2)

--> "Every morning the sun rises. Right towards the plains illuminating the coffee plants". (14th narrative, line 2)

Love (mentioned three times)

--> "they think of it as a cheap place to visit and a quick escape from their reality, they fall in love with the coffee". (7th narrative, line 4)

--> "There are many kind persons with a huge capacity to give love to others and passionate about the plains". (12th narrative, line 2) 
--> "Colombia is synonym for beauty, in every corner of this country resides a living story of our ancestors, a story of love, freedom, courage, combat, and belief ". (13th narrative, line 4)

Artists (mentioned three times)

--> "Colombian people have much talent by their: athletics, writers, artists, and so forth". (6th narrative, line 5)

--> "Without forgetting the warmth and friendliness of its inhabitants, fantastic and talents writers, artists, athletes, singers, etc". (8th narrative, line 4)

--> "The most beautiful of this country is the nature, our natives, the different dialects, the carnivals, artists and more". (13th narrative, line 2)

Carnivals (mentioned twice)

--> "We have amazing gastronomy, carnivals that allow us to tell our history with the representative Colombian joy and ingenuity". (8th narrative, line 2)

--> "The most beautiful of this country is the nature, our natives, the different dialects, the carnivals, artist and more". (13th narrative, line 2)

Landscapes (mentioned twice)

--> "Colombia, a country of contrasts. Colombia has been recognized for its natural resources and landscapes for years...". (4th narrative, line 1)

"For example, in its landscapes: it is amazing to see how you can go from a great desert like Cabo de la Vela, to a humid jungle like El Amazonas...". (11th narrative, line 3)

Happiness (mentioned twice)

--> "As a Colombian inhabitant I feel both: proud and happiness for living in a marvelous country like this". (4th narrative, line 5)

--> "Only here, you can appreciate either a really good party or a danceable advertisement, while still feeling that happiness that never dies". (15th narrative, line 6)

Coffee (mentioned 6 times)

--> "they think of it as a cheap place to visit and a quick escape from their reality, they fall in love with the coffee...". (7th narrative, line 4)

--> "Our coffee is unrivalled. Vallenato, Cumbia, Porro and Bullerengue give us the heebie-jeebies when they are played anywhere." (9th narrative, line 4)

--> "Colombia the land of hope in coffee." (14th narrative, line 1)

--> "Right towards the plains illuminating the coffee plants." (14th narrative, line 2)

--> "Coffee is sold by hardworking hands who stand up at dawn..." (14th narrative, line 5)

--> "these hands are synonymous with those who collect coffee..." (14th narrative, line 5)

Within the codes named positive adjective-noun collocations the commonest lexical collocations were:

Beautiful country (mentioned twice in the narratives)

-> "Colombia is a beautiful country with wonderful landscapes and places". (6th narrative, line 1)

--> "Colombian paradise hidden in hell Colombia is a beautiful country, with a very interesting history and a unique cultural diversity". (8th narrative, line 1)

Natural resources (mentioned twice)

--> "Currently speaking of Colombia as Colombian is ambiguous, I consider Colombia has a great potential at the human level, natural resources, gastronomy, culture, etc". (1st narrative, line 1)

--> "Colombia has been recognized for its natural resources and landscapes for years, but for its poor efforts for protecting them as well". (4th narrative, line 1)

and kind people (mentioned twice)

Kind people (mentioned twice)

--> "Colombia is known for its stunning landscapes, startling nature and kind people but when it comes to tourism..." (7th narrative, line 1) 
--> "There are many kind persons with a huge capacity to give love to others and passionate about the plains." (12th narrative, line 2)

Within the codes labelled negative nouns the commonest terms used by student-teachers were:

The commonest words mentioned within the label negative nouns were:

Corruption (mentioned seven times in the narratives)

--> "They are an endless number of beautiful things that Colombia has; however, we also have negative aspects; such as drug trafficking, corruption, misleading politicians, etc". (1st narrative, line 3)

--> "Colombians continue to consume and support these failures, the creation and support of Narconovelas, music with this same meaning, support for political parties and corruption with phrases like "almenos no nos robaron tanto". (At least they did not steal that much from us) (1st narrative, line 6)

--> "Colombian people are happy and strong despite of living in a country where there is no gender equality, where there are constantly references to drugs, violence, the disappearance of people, corruption, prostitution, child abuse". (3rd narrative, line 4)

--> "Every Colombian can be proud about it. However, the Colombian Government is characterized by its corruption, impunity and a poor administration on protecting the environment and the population in general". (4th narrative, line 3)

--> "...and another thing more important is that Colombian people are very sociable and friendly in spite of social problems such as the war, corruption and drug trafficking". (6th narrative, line 6)

--> "Our country has unkind features as drug trafficking, corruption and an apparently endless violence". (9th narrative, line 1)

--> "However, a dark color has been falling over Colombia for many years: wars, injustice, corruption, indolence, government abandonment and many other terrible things". (13th narrative, line 5)

Drug trafficking (mentioned four times)

--> "There are an endless number of beautiful things that Colombia has; however, we also have negative aspects; such as drug trafficking, corruption, misleading politicians, etc". (1st narrative, line 3)

--> "and another thing more important is that Colombian people are very sociable and friendly in spite of social problems such as the war, corruption and drug trafficking". (6th narrative, line 6)

--> "Represent Colombian talent, however, this sole paradise is ignored and is commonly recognized by drug trafficking and war that has been torturing the poorest". (8th narrative, line 6)

--> "Suffering but Glorious / Being Colombian means to see both sides of the coin. Our country has unkind features as drug trafficking, corruption and an apparently endless violence". (9th narrative, line 1)

War (mentioned twice)

--> "Represent Colombian talent, however, this sole paradise is ignored and is commonly recognized by drug trafficking and war that has been torturing the poorest". (8th narrative, line 6)

--> "However, a dark color has been falling over Colombia for many years: wars, injustice, corruption, indolence,

government abandonment and many other terrible things". (13th narrative, line 5)

Within the label negative adjective-noun collocations there were 14 lexical collocations. Each of them was mentioned just once throughout the narratives.

\subsection{Second Coding Phase Results}

The second coding phase was carried out by ranking the 254 codes found in the first coding stage into open codes depending on the aspects they referred to. In this vein, 8 new labels appeared: cultural, natural, human, geographic, political, culinary, economic, and social aspects. Table 2 shows the crossed-tabulation final results. 
Table 2. Second Coding Phase: Views on Colombia

\begin{tabular}{llllll}
\hline aspects & positive nouns & negative nouns & $\begin{array}{l}\text { positive adjective-noun } \\
\text { collocations }\end{array}$ & $\begin{array}{l}\text { negative adjective-noun } \\
\text { collocations }\end{array}$ & Total \\
\hline cultural & 29 & 5 & 26 & & 60 \\
natural & 12 & 4 & 28 & 2 & 46 \\
human & 27 & 4 & 13 & 1 & 37 \\
geographic & 19 & 3 & 15 & 7 & 24 \\
political & 1 & 15 & 1 & & 22 \\
culinary & 14 & & 8 & 1 & 13 \\
economic & 3 & 7 & 2 & 3 & 7 \\
social & 105 & 4 & 93 & 14 & 254 \\
Total & 42 & 93 & & \\
\hline
\end{tabular}

As depicted in Table 2, the codes labelled cultural aspects are the most frequent ones in terms of the views participants have about their country, with a $23.62 \%$ of the 254 codes which emerged in the coding phases. Out of these 60 cultural aspect codes, $48.33 \%$ belong to positive nouns, $43.33 \%$ correspond to the positive adjective-noun collocations, $8.33 \%$ account for negative nouns, and there were no cultural aspects related to the negative adjective-noun collocations codes. If we add the number of positive nouns codes to the positive adjective-noun collocations codes, we obtain a figure of 55 codes, which represents a remarkable $91.66 \%$ of the total number of codes labelled cultural aspects. This indicates that participants have a highly positive view about their country in terms of cultural aspects. Furthermore, it reveals that positive codes outnumber negative codes greatly when it comes to cultural traits. Concerning the ratio, for every negative cultural aspect code present in the narratives, there are roughly 11 positive cultural aspect codes.

The codes labelled natural aspects rank second in terms of frequency when we talk about views student-teachers hold about their country, with an $18.11 \%$ of the 254 codes obtained in the coding stages. Out of the 46 natural aspects codes, $11.02 \%$ are connected to the positive adjective-noun collocations, $4.72 \%$ are related to positive nouns, $1.96 \%$ account for negative nouns and $0.78 \%$ represent the negative adjective-noun collocations. Adding the percentages for positive codes (positive nouns and positive adjective-noun collocations), we obtain a $15.75 \%$ which surpasses the low percentage of negative codes (2.74\%). This unveils that the perceptions participants have about Colombia in terms of natural traits tend to be positive. It also stresses out that as for ratio, every time student-teachers mention a negative natural aspect code, they use nearly 5 positive codes in terms of natural traits in the narratives.

The codes called human aspects are the third most frequent labels regarding views participants have about their nation, with a $17.71 \%$ of the total number of codes (254). Out of the 45 human aspects codes, $60 \%$ account for positive nouns, $28.88 \%$ represent the positive adjective-noun collocations, $8.88 \%$ correspond to negative nouns, and $2.22 \%$ are connected to the negative adjective-noun collocations. If positive codes are added, we obtain 40 codes, which account for the $88.88 \%$ of the human aspects codes. This very high percentage exceeds largely the $11.10 \%$ of negative codes. This reveals that the perception student-teachers hold about their country is highly positive concerning human aspects. As for ratio, every time participants refer to a negative code, they use 8 positive codes in terms of human traits.

The codes entitled geographic aspects occupy the fourth position concerning frequency of views student-teachers hold about Colombia, with a $14.56 \%$ of total number codes which emerged in the coding phases. Out of the 37 geographic aspects codes, $51.35 \%$ are associated with positive nouns, $40.54 \%$ are connected to the positive adjective-noun collocations and $8.10 \%$ are linked to negative nouns. It is worth mentioning that participants did not use any negative adjective-noun collocations to refer to geographic aspects. Adding positive codes, we obtain a figure of 34 , which represents the $91.89 \%$ of the geographic aspects codes. This pinpoints that once again; the percentage of positive codes considerably outnumbers the percentage of the negative ones, and that participants' views about Colombian in terms of geographic traits is likely to be quite positive. Regarding ratio, every time a student-teacher mentions a negative code, they use 11 positive codes when talking about geographic characteristics about Colombia.

The fifth position concerning views on Colombia held by participants is occupied by the codes named political aspects, with a $9.44 \%$ of the total number of codes obtained in the counting phases. Out of the 24 political 
aspects codes, $62.5 \%$ represent negative nouns, $29.16 \%$ account for negative adjective-noun collocations, $4.16 \%$ refer to positive nouns and $4.16 \%$ make reference to positive adjective-noun collocations. If we add the percentage of negative codes, we get $91.21 \%$, which contrasted to the $8.32 \%$ of positive codes, revealing that for the first time in the analysis the codes implying something negative about Colombia largely exceed the ones entailing something positive. This also means that participants have a negative idea about their country when they talk about aspects related to politics. In terms of ratio, every time a student-teacher makes use of a positive code, they mention almost 11 negative codes.

The sixth place in relation to the frequency of views participants have about their nation is taken by the codes labelled as culinary aspects, with an $8.66 \%$ of total number of codes obtained in the counting stages (254). Out of the 22 culinary aspects codes, $63.63 \%$ are connected to positive nouns and $36.36 \%$ are linked to positive adjective-noun collocations. This implies that participants have fairly high optimistic views about Colombia regarding its gastronomy, and that for the first time in the analysis, no negative codes are found with respect to an aspect about this nation.

The codes named economic aspects rank seventh regarding frequency of views on Colombia, with a $5.11 \%$ of total number of codes found in the counting phases (254). Out of the 13 economic aspects codes, $53.84 \%$ refer to negative nouns, 23.07 correspond to positive nouns, $15.38 \%$ account for positive adjective-noun collocations and $7.69 \%$ make reference to negative adjective-noun collocations. Adding the percentages of negative codes, we obtain $61.53 \%$, which contrasted to the percentage of positive codes $(38.45 \%)$, tells us that for the second time in the analysis negative codes surpass the positive codes in an aspect. Moreover, this unveils tha student-teachers do not have a positive opinion when they refer to political aspects of their country. About ratio, we can see that every time participants refer to a positive code, they mention approximately 1.5 negative codes.

The last place in terms of frequency of views on Colombia that student-teachers have is occupied by the codes entitled social aspects, with a $2.75 \%$ of total number of codes counted (254). Out of the 7 codes for social aspects, $57.14 \%$ refer to negative nouns, and $42.85 \%$ correspond to negative adjective-noun collocations, implying that for the third time in the analysis, negative codes surpass positive codes, and also that for the first time in the analysis, no positive codes are found in one of the aspects. This reveals another important fact: participants hold a very negative opinion about their nation when talking about social aspects, being the only aspect in which no positive characteristics or traits were evoked.

\subsubsection{Most Frequent Words Found in Second Coding Phase Results}

Cultural codes. Within the codes called cultural aspects, the commonest positive nouns found in the narratives were:

\section{Stories}

--> "Hundreds of stories dwell inside each town and city". (10th narrative, line 3)

--> "All this means that we have different worldviews and that our stories are told in different ways." (11th narrative, line 6)

Magic

--> "Beyond Magic It is said that Colombia bewitches everyone who lands in its ground". (10th narrative, line 1)

--> "However, beyond all the magic that this country offers, there is still struggle and probably that's the best way to describe this land and the people who live on it. People who, even when surrounded by magic, have to struggle". (10th narrative, line 4)

--> "A place where magic comes true, where joyfulness comes in all shapes and sizes, even the little things". (15th narrative, line 4$)$

\section{Festivals}

--> "Colombia's first destination was El Eje Cafetero, where she could drink the best coffee ever and could enjoy the Festival of the Flowers". (2nd narrative, line 5)

--> "Colombia is mostly catholic; it has many fairs and festivals in each one of 32 departments...". (6th narrative, line 3)

\section{Carnivals}

--> "We have amazing gastronomy, carnivals that allow us to tell our history with the representative Colombian joy and ingenuity", (8th narrative, line 2 
--> "The most beautiful of this country is the nature, our natives, the different dialects, the carnivals, artist and more". (13th narrative, line 2)

\section{History}

--> "We have amazing gastronomy, carnivals that allow us to tell our history with the representative". (8th narrative, line 2)

--> "The Dark Paradise Colombia is a magical country full of a variety of history". (13th narrative, line 1)

There were 26 different positive-adjective noun collocations within the codes labelled cultural aspects. None of them was repeated.

There were only five negative nouns making reference to cultural aspects. None of them were repeated.

There were not any negative adjective-noun collocations associated to culturals aspects.

Natural aspects codes. The commonest positive nouns in this label were:

\section{Beauty}

--> "it is not a secret how expensive it could be for a native person to travel around and get to enjoy the beauty of the country..." (7th narrative, line 2)

--> "There are unique landscapes, where you can see the beauty of this country." (8th narrative, line 3)

\section{Nature}

--> "The most beautiful of this country is the nature, our natives, the different dialects, the carnivals, artist and more." (13th narrative, line 2)

--> "You can let you marvel at the beauties that nature offers or you can simply enjoy a good conversation with a stranger." (15th narrative, line 5)

\section{Coffee}

--> "Our coffee is unrivalled." (9th narrative, line 4)

--> "Colombia the land of hope in coffee." (14th narrative, line 1)

--> "Right towards the plains illuminating the coffee plants." (14th narrative, line 2)

--> "Coffee is sold by hardworking hands who stand up at dawn..." (14th narrative, line 5)

--> "these hands are synonymous with those who collect coffee." (14th narrative, line 5)

\section{Plains}

--> "There are many kind persons with a huge capacity to give love to others and passionate about the plains". (12th narrative, line 2)

--> "Every morning the sun rises. Right towards the plains illuminating the coffee plants". (14th narrative, line 2)

The commonest positive adjective-noun collocations were:

beautiful country (mentioned twice in the narratives)

-> "Colombia is a beautiful country with wonderful landscapes and places". (6th narrative, line 1)

--> "Colombian paradise hidden in hell Colombia is a beautiful country, with a very interesting history and a unique cultural diversity". (8th narrative, line 1)

natural resources (mentioned twice)

--> "Currently speaking of Colombia as Colombian is ambiguous, I consider Colombia has a great potential at the human level, natural resources, gastronomy, culture, etc". (1st narrative, line 1)

--> "Colombia has been recognized for its natural resources and landscapes for years, but for its poor efforts for protecting them as well". (4th narrative, line 1)

There were only two negative adjective-noun collocations in terms of natural aspects.

There were four negative nouns within the natural aspects codes. Needlees to say, they were mentioned once apiece.

Human aspects codes. Within the human aspects codes, the commonest positive nouns found were:

Happiness (mentioned twice in the narratives) 
--> "As a Colombian inhabitant I feel both: proud and happiness for living in a marvelous country like this..." (4th narrative, line 5)

--> "Only here, you can appreciate either a really good party or a danceable advertisement, while still feeling that happiness that never dies." (15th narrative, line 6)

Writers (mentioned twice)

--> "Colombian people have much talent by their: athletics, writers, artists, and si forth." (6th narrative, line 5)

--> "Without forgetting the warmth and friendliness of its inhabitants, fantastic and talents writers, artists, athletes, singers, etc." (8th narrative, line 4)

Artists (mentioned twice)

--> "Colombian people have much talent by their: athletics, writers, artists, and si forth." (6th narrative, line 5)

--> "Without forgetting the warmth and friendliness of its inhabitants, fantastic and talents writers, artists, athletes, singers, etc." (8th narrative, line 4)

--> "Colombia is a magical country full of a variety of history. The most beautiful of this country is the nature, our natives, the different dialects, the carnivals, artist and more." (13th narrative, line 1)

Talent (mentioned thrice)

--> "Colombian people have much talent by their: athletics, writers, artists, and si forth." (6th narrative, line 5)

--> "Without forgetting the warmth and friendliness of its inhabitants, fantastic and talents writers, artists, athletes, singers, etc." (8th narrative, line 4)

--> "Represent Colombian talent, however, this sole paradise is ignored and is commonly recognized by drug trafficking and war that has been torturing the poorest." (8th narrative, line 6)

Joy (mentioned four times)

--> "We have amazing gastronomy, carnivals that allow us to tell our history with the representative Colombian joy and ingenuity." (8th narrative, line 2)

--> "Colombia: The land of everlasting joy." (15th narrative, line 1)

--> "Waking up with the idea in mind that "early bird gets the worm", just happen here, in the land of everlasting joy." (15th narrative - line 3 )

--> "A place where magic comes true, where joyfulness comes in all shapes and sizes, even the little things." (15th narrative, line 4)

Love (mentioned thrice)

--> "they think of it as a cheap place to visit and a quick escape from their reality, they fall in love with the coffee." (7th narrative, line 4)

--> "There are many kind persons with a huge capacity to give love to others and passionate about the plains." (12th narrative, line 2)

--> "Colombia is synonym for beauty, in every corner of this country resides a living story of our ancestors, a story of love, freedom, courage, combat, and belief." (13th narrative, line 4)

There was just one positive noun-adjective collocation:

Kind people (mentioned twice)

--> "Colombia is known for its stunning landscapes, startling nature and kind people..." (7th narrative, line 1)

--> "There are many kind persons with a huge capacity to give love to others and passionate about the plains." (12th narrative, line 2)

There was not one negative noun-adjective collocation referring to human aspects.

There were no negative nouns being repeated.

Geographic aspects codes. The commonest positive nouns within this label were:

Eje cafetero (mentioned twice)

--> "Colombia's first destination was El Eje Cafetero, where she could drink the best coffee ever and could enjoy the Festival of the Flowers." (2nd narrative, line 5) 
--> "it is amazing to see how you can go from a great desert like Cabo de la Vela, to a humid jungle like El Amazonas, or from a plain area like Los LLanos Orientales to a mountainous area like the Eje Cafetero." (11th narrative, line 4)

Plains (mentioned four times)

--> "Therefore, she decided to move to the Orinoco plains." (2nd narrative, line 14)

--> "In Colombia you can find magical places, tropical paradises, crystalline seas and rivers, great plains and exotic animals." (3rd narrative, line 3)

--> "There are many kind persons with a huge capacity to give love to others and passionate about the plains." (12th narrative, line 2)

--> "Every morning the sun rises. Right towards the plains illuminating the coffee plants." (14th narrative, line 2)

Llanos orientales (mentioned twice)

--> "it is amazing to see how you can go from a great desert like Cabo de la Vela, to a humid jungle like El Amazonas, or from a plain area like Los LLanos Orientales to a mountainous area like the Eje Cafetero." (11th narrative, line 4)

--> "This small village is called Pore Casanare that is located in Los Llanos Orientales." (12th narrative, line 3)

There were three negative nouns within the geographic aspects. None of them were repeated.

There were 15 positive adjective-noun collocations. None of them were repeated.

There were not any negative adjective-noun collocations in this label.

\section{Political aspects codes}

There was only one positive political aspect noun.

The most frequent negative aspects nouns were:

\section{Corruption}

--> "They are an endless number of beautiful things that Colombia has; however, we also have negative aspects; such as drug trafficking, corruption, misleading politicians, etc." (1st narrative, line 3)

--> "Colombians continue to consume and support these failures, the creation and support of Narconovelas, music with this same meaning, support for political parties and corruption with phrases like "almenos no nos robaron tanto" (At least they did not steal that much from us) (1st narrative, line 6)

--> "Colombian people are happy and strong despite of living in a country where there is no gender equality, where there are constantly references to drugs, violence, the disappearance of people, corruption, prostitution, child abuse." (3rd narrative, line 4)

--> "Every Colombian can be proud about it. However, the Colombian Government is characterized by its corruption, impunity and a poor administration on protecting the environment and the population in general." (4th narrative, line 3)

--> "...and another thing more important is that Colombian people are very sociable and friendly in spite of social problems such as the war, corruption and drug trafficking." (6th narrative, line 6)

--> "Our country has unkind features as drug trafficking, corruption and an apparently endless violence." (9th narrative, line 1)

--> "However, a dark color has been falling over Colombia for many years: wars, injustice, corruption, indolence, government abandonment and many other terrible things." (13th narrative, line 5)

\section{War}

--> "Represent Colombian talent, however, this sole paradise is ignored and is commonly recognized by drug trafficking and war that has been torturing the poorest." (8th narrative, line 6)

--> "However, a dark color has been falling over Colombia for many years: wars, injustice, corruption, indolence, government abandonment and many other terrible things." (13th narrative, line 5)

There was only one positive adjective-noun collocation within this label.

There were not repeated negative adjective-noun collocations within the label political aspects. 


\section{Culinary aspects codes}

There was just one positive noun within this label being repeated:

Ajiaco (Typical chicken and potatoes soup/repeated twice)

--> "She stayed over there just for a week. Even though she could taste typical dishes such as ajiaco, changua, chocolate with cheese, and empanada for the first three days, she was stolen for a gang of black vultures on the fourth day." (2nd narrative, line 9)

--> "Colombia is mostly catholic; it has many fairs and festivals in each one of 32 departments; food is varied and exquisite, for example, Ajiaco, Mondongo, Carne a la llanera, la butifarra and so on..." (6th narrative, line 3)

There were no positive adjective-noun collocations, negative nouns and negative adjective-noun collocations repeated within the culinary aspects label.

\section{Economic aspects codes}

The commonest negative noun within this label was:

Drug trafficking (repeated four times)

--> "They are an endless number of beautiful things that Colombia has; however, we also have negative aspects; such as drug trafficking, corruption, misleading politicians, etc." (1st narrative, line 3)

--> "and another thing more important is that Colombian people are very sociable and friendly in spite of social problems such as the war, corruption and drug trafficking." (6th narrative, line 6)

--> "Represent Colombian talent, however, this sole paradise is ignored and is commonly recognized by drug trafficking and war that has been torturing the poorest." (8th narrative, line 6)

--> "Suffering but Glorious / Being Colombian means to see both sides of the coin. Our country has unkind features as drug trafficking, corruption and an apparently endless violence." (9th narrative, line 1)

There were no negative nouns and negative adjective-noun collocations found in this label.

There were not positive adjective-noun collocations repeated within the culinary aspects.

\section{Social aspects codes}

There were no positive nouns and positive adjective-noun collocations found in this label.

There were no negative nouns and negative adjective-noun collocations repeated within the social aspects.

\subsection{Results from Second Written Narratives}

In second written narratives, participants were requested to write an $80-100$-word text in which they expressed their views and feelings about themselves as Colombians. The variable being measured here was labelled Views on Own Identity, and the unit of analysis were the adjectives which participants used to refer to themselves as Colombian citizens.

\subsubsection{First Coding Phase Results}

The first coding phase was conducted by classifying all adjectives into negative and positive, according to the context in which they appeared, and the interpretation researchers made about the way they were used in the second written narratives.

Table 3. First Coding Phase: Views on Own Identity

\begin{tabular}{lll}
\hline positive adjectives & negative adjectives & Total \\
\hline 24 & 2 & 26 \\
\hline
\end{tabular}

Table 3 reveals that codes labelled positive adjectives account for the most frequent views that participants hold about themselves as Colombians, with a $92.30 \%$ of the 26 codes obtained in this phase. Conversely, the negative adjectives codes correspond to the least common views student-teachers have about their identity as Colombians, with a $7.69 \%$ of the total number of codes obtained in this stage (26).

This information depicts that participants have a highly optimistic self-concept as Colombians, and that these quite positive views exceed the negative notions about themselves by almost $85 \%$. This also conveys that in terms of ratio, every time they mentioned one of the negative adjectives in the narratives, 13 positive adjectives were referred to. 


\subsubsection{Most Frequent Words Found in First Coding Phase}

The commonest positive adjectives within the second narratives were:

Kind (mentioned twice)

--> "I am collaborative; I am cheerful, funny, kind and I remind them how important they are to their family..." (1st narrative, line 4)

--> "A real Colombian I believe that Colombians are happy, enterprising, authentic, kind and creative." (3rd narrative, line 1)

Proud (mentioned twice)

--> "I love so much my country and I feel proud to be a colombian." (6th narrative, line 11)

--> "Nonetheless, I go anywhere with my umbrella as a good Bogotan and I live proud of our landscapes and nature. (8th narrative, line 7)

--> "I'm proud to be Colombian not because she is the best but because she seems my mother." (10th narrative, line 6)

Funny (mentioned twice)

--> "I am collaborative; I am cheerful, funny, kind and I remind them how important they are to their family..." (1st narrative, line 4)

--> "But being Colombia it's funny too, when I was talking with a north American girl she asked me if Escobar's soap operas still happen..." (14th narrative, line 2)

Authentic (mentioned thrice)

--> "I consider myself as an authentic Colombian girl, maybe a common one but at least one who loves her country, who knows its social problems, and who dreams with a better future." (2nd narrative, line 1)

--> "A real Colombian I believe that Colombians are happy, enterprising, authentic, kind and creative." (3rd narrative, line 1)

--> "I feel Colombian for understanding the importance of our rich culture. I am authentic and love my nation" (4th narrative, line 7)

There were just two negative adjectives in the second written narratives. Thus, no frequent negative codes were found in this label.

\subsubsection{Second Coding Phase Results}

This second coding stage was done out by ranking the 26 codes found in the first coding stage into open codes depending on the attributes or defects they referred to. In this fashion, 4 new labels appeared: personality, mood, character, and appearance. Table 4 displays the crossed-tabulation final results.

Table 4. Second Coding Phase: Views on Own Identity

\begin{tabular}{llll}
\hline types of adjectives & positive adjectives & negative adjectives & Total \\
\hline personality & 13 & 1 & 14 \\
mood & 7 & & 7 \\
character & 4 & 1 & 4 \\
appearance & & 2 & 1 \\
Total & 24 & 26 \\
\hline
\end{tabular}

As shown in Table 4, the codes named personality are on top in terms of frequency of views participants have about themselves as Colombian citizens, with a $53.84 \%$ of the 26 codes which emerged in the two coding stages. Out of these 14 personality codes, $92.85 \%$ correspond to positive adjectives, and $7.14 \%$ account for negative adjectives. This unveils the fact that participants have a very high view on themselves as Colombians when referring to personality traits or features. It also reveals that the personality positive adjectives codes significantly outnumber the personality negative adjectives codes by 85.71. Regarding ratio, every time student-teachers mention a negative adjective in terms of personality, they use 13 positive adjectives.

The codes labelled mood occupy the second position when it comes to frequency of views student-teachers hold about themselves as Colombians, with a 50\% of the total number of codes (26). Strikingly, all the 7 mood codes 
correspond to positive adjectives. This unveils that prospective teachers have fairly high views when describing their state of minds and feelings as Colombians, and that they do not find any negative aspects regarding their temper.

The codes entitled character rank third with respect to the self-concept participants hold about themselves as Colombians, with a $15.38 \%$ of the 26 codes obtained in the counting phases. As it happened with the mood codes, all the 4 character codes correspond to positive adjectives, implying that student-teachers think highly of themselves when talking about their nature, and suggesting that they do not associate any negative aspects with their disposition as Colombian people.

The appearance codes rank at the bottom regarding frequency of views participants have about themselves as citizens from Colombia, with a $3.86 \%$ of total number of codes which emerged in the coding phases (26). The only code obtained in this label corresponds to a negative adjective. This means that in general terms, participants in the study do not really tend to think of physical traits or characteristics when defining themselves as Colombians.

\subsubsection{Most Frequent Words Mentioned in Second Coding Phase}

The commonest words found in this stage were:

\section{Personality codes}

Authentic (mentioned thrice)

--> "I feel Colombian for understanding the importance of our rich culture. I am authentic and love my nation." (4th narrative, line 7)

--> "I consider myself as an authentic Colombian girl, maybe a common one but at least one who loves her country, who knows its social problems, and who dreams with a better future." (2nd narrative, line 1)

--> "A real Colombian I believe that Colombians are happy, enterprising, authentic, kind and creative." (3rd narrative, line 1)

Kind (mentioned twice)

--> "I am collaborative; I am cheerful, funny, kind and I remind them how important they are to their family..." (1st narrative, line 4)

--> "A real Colombian I believe that Colombians are happy, enterprising, authentic, kind and creative." (3rd narrative, line 1)

\section{Mood codes}

Proud (mentioned thrice)

--> "I love so much my country and I feel proud to be a colombian." (6th narrative, line 11)

--> "Nonetheless, I go anywhere with my umbrella as a good Bogotan, and I live proud of our landscapes and nature. (8th narrative, line 7)

--> "I'm proud to be Colombian not because she is the best but because she seems my mother." (10th narrative, line 6)

\section{Funny (mentioned twice)}

--> "I am collaborative; I am cheerful, funny, kind and I remind them how important they are to their family..." (1st narrative, line 4)

--> "But being Colombia it's funny too, when I was talking with a north American girl, she asked me if Escobar's soap operas still happen..." (14th narrative, line 2)

There were four character codes. None of them were repeated.

There was just one appearance code.

\subsection{Results from Oral Narratives}

In the oral narratives, participants were requested to tell an 80-100-story in which they expressed their perceptions and impressions about Colombians in general. The variable measured here was labelled Views on Colombians, and the unit of analysis were the adjectives which participants used to refer to their co-nationals in general. 


\subsubsection{First Coding Phase Results}

The first coding phase was completed by assorting all adjectives into negative and positive, according to the context in which they appeared, and the interpretation researchers made about the way they were used in the oral narratives.

Table 5. First Coding Phase: Views on Colombians

\begin{tabular}{lll}
\hline positive adjectives & negative adjectives & Total \\
\hline 29 & 18 & 47 \\
\hline
\end{tabular}

Table 5 shows that codes labelled positive adjectives correspond to the most frequent views that participants hold about Colombians in general, with a $61.70 \%$ of the 47 codes obtained in this phase. On the other hand, the negative adjectives codes represent the least common views student-teachers have about their co-nationals, with a $38.29 \%$ of the total number of codes obtained in this stage.

This information shows that participants have an optimistic view on Colombians in general, and that these very positive views surpass the negative perceptions about their co-nationals by $13.85 \%$. This also conveys that in terms of ratio, every time they mentioned one of the negative adjectives in the narratives, 4 positive adjectives were evoked.

\subsubsection{Most Frequent Words Mentioned in First Phase}

The commonest terms which emerged in this stage were:

\section{Positive adjectives}

Respectful (mentioned twice)

--> "Efrain is a very honest and respectful guy." (6th narrative, line 1)

--> "Pancho is a very nice and kind men, he is respectful and loyal, but he is very innocent." (7th narrative, line 2)

Beautiful (mentioned thrice)

--> "He has a good health a beautiful family." (7th narrative, line 3)

--> "Colombians are diverse and beautiful inside but damage by others..." (10th narrative, line 1)

--> "Yes, we are a place a beautiful place that everyone knows how to appreciate but nobody knows how to value." (10th narrative, line 3)

\section{Negative adjectives}

\section{Little (mentioned thrice)}

--> "the story of some one that live in Antioquia and who live in Apartadó, and he is a little man has some particular..." (1st narrative, line 1)

--> "However, that day, narconovelas were talking about a politician and the relation with the narcotrafico, and this little men was indignant because he didn't think that the history could be true." (1st narrative, line 6)

--> "Fortunately, one of his friends told him like, eyy, I have a big opportunity for you. I have a job opportunity and you can go and work, but we are going to give you some instructions, little instructions that you just need to develop, and you don't have to ask questions you are gonna have a lot of money..." (4th narrative, line 6)

Sad (mentioned twice)

--> "Andres was sad and alone, he wanted to share something that he had just discovered." )12th narrative, line 12)

--> "She felt very sad." (13th narrative, line 5)

\subsection{Second Coding Phase Results}

This second coding stage was done out by ranking the 47 codes found in the first coding stage into open codes depending on the attributes or defects they referred to. In this fashion, 6 new labels appeared: appearance, mood, moral quality, personality, social approval, and character. Table 6 displays the crossed-tabulation results. 
Table 6. Second coding phase views on Colombians

\begin{tabular}{llll}
\hline types of adjectives & positive adjectives & negative adjectives & Total \\
\hline personality & 13 & 1 & 14 \\
mood & 7 & & 7 \\
character & 4 & 1 & 4 \\
appearance & & 2 & 1 \\
Total & 24 & 1 & 26 \\
\hline
\end{tabular}

As shown in Table 6, the codes named mood occupy the first place in terms of frequency of views participants have about Colombians in general, with a $25.53 \%$ of the 47 codes which emerged in the two coding phases. Out of these 12 mood codes, $75 \%$ correspond to negative adjectives, and $25 \%$ account for positive adjectives. This shows that student-teachers have a very negative view on their co-nationals when referring to feelings, emotions, or moods. It also reveals that the mood negative adjective codes considerably outnumber the mood positive adjective codes by $50 \%$. Regarding ratio, every time student-teachers mention a positive adjective in terms of mood, they use 3 positive adjectives.

The codes labelled personality rank second position when it comes to frequency of views student-teachers hold about their compatriots, with a $23.40 \%$ of the total number of codes (47). Out of the 11 personality codes, $72.72 \%$ represent positive adjectives and $27.27 \%$ correspond to negative adjectives. This unveils that future teachers have high views when describing their fellow-citizens in terms of personality. The positive views surpass the negative ones by $45.45 \%$, and concerning ratio, every time a negative adjective for personality is mentioned, 2.6 positive adjectives are brought up.

The codes entitled character rank third with respect to the perception participants hold about Colombians in general, with a $17.02 \%$ of the 47 codes obtained in the counting phases. Out of the 8 character codes, $87.5 \%$ account for positive adjectives, and $12.5 \%$ correspond to negative adjectives. This means that the views student-teachers hold about their co-nationals in relation to character tend to be highly positive, and that positive perceptions surpass the negative ones by $75 \%$. In terms of ratio, every time a negative adjective is used in the narratives, 7 positive adjectives are conveyed.

The moral quality codes are placed in fourth position in terms of views student-teachers have about Colombians in general, with $12.7 \%$ of the codes obtained in the coding phases (47). Out of the 6 moral quality codes, $83.33 \%$ represent positive adjectives and $16.66 \%$ correspond to negative adjectives. This reveals that the views respondents have about their compatriots tend to be highly positive, and that those positive views outnumber the negative ones by $66.67 \%$. Regarding ratio, every time a negative adjective is mentioned, 5 positive adjectives are referenced.

The codes named appearance and social approval occupy the last position in terms of views on Colombians, with $10.63 \%$ each one. Out of the 5 appearance codes, $80 \%$ refer to positive adjectives, and $20 \%$ to negative adjectives, showing that perceptions prospective teachers have about their co-nationals concerning their physical appearance are very positive, and that these positive views surpass the negative ones by $60 \%$. In terms of ratio, we find that for the negative adjective mentioned in this label, participants referenced 4 positive adjectives.

On the other hand, out of the 5 social approval codes, $60 \%$ make reference to negative adjectives, and $40 \%$ to positive adjectives, revealing that views on Colombians in general, in terms of how socially they are valued and perceived, tend to be more negative than positive. The negative perceptions exceed the positive ones by $20 \%$. In relation to ratio, every time a positive adjective is mentioned in this label, 1.5 negatives adjectives are implied.

\subsubsection{Most Frequent Words Found in the Second Coding Phase}

The commonest terms mentioned in this stage were:

\section{Personality adjectives codes}

Respectful (mentioned twice)

--> "Efrain is a very honest and respectful guy." (6th narrative, line 1)

--> "Pancho is a very nice and kind men, he is respectful and loyal, but he is very innocent." (7th narrative, line 2) 


\section{Beautiful (mentioned thrice)}

--> "He has a good health a beautiful family." (7th narrative, line 3)

--> "Colombians are diverse and beautiful inside but damage by others..." (10th narrative, line 1)

--> "Yes, we are a place a beautiful place that everyone knows how to appreciate but nobody knows how to value." (10th narrative, line 3)

\section{Mood adjectives codes}

Sad (mentioned twice)

--> "Andres was sad and alone, he wanted to share something that he had just discovered." )12th narrative, line $12)$

--> "She felt very sad." (13th narrative, line 5)

Happy (mentioned twice)

--> "Pancho is a very happy farmer." (7th narrative, line 1)

--> "He is happy." (7th narrative, line 3)

There are no words repeated withing the character codes

\section{Appearance codes}

\section{Little (mentioned four times)}

--> "the story of some one that live in Antioquia and who live in Apartadó, and he is a little man has some particular..." (1st narrative, line 1)

--> "However, that day narconovelas were talking about a politician and the relation with the narcotrafico, and this little men was indignant because he didn't think that the history could be true." (1st narrative, line 6)

--> "Fortunately, one of his friends told him like, eyy, I have a big opportunity for you. I have a job opportunity and you can go and work, but we are going to give you some instructions, little instructions that you just need to develop, and you don't have to ask questions you are gonna have a lot of money..." (4th narrative, line 6)

--> "OK, my story is called the strength of a little woman." (14th narrative, line 1)

\section{Moral quality codes}

There are no words repeated within the 6 moral codes.

\subsection{Results from Questionnaire}

The 15 participants were asked to respond to a final survey intended to confirm the quantitative information obtained from the narratives. In question number one, they were requested to provide an accurate account on views about their country. Answers to first question unveil that $13.3 \%$ of participants have slightly negative views about Colombia, another $13.3 \%$ hold relatively neuter views about their country (meaning not positive, not negative), $20 \%$ have slightly positive views about their nation, $40 \%$ hold positive views about their republic, and the remaining $13.14 \%$ have very positive views about Colombia. If we add positive percentages, we find that $73.14 \%$ of respondents hold positive views about their country, contrasted to the $13.3 \%$ of student-teachers who have negative views about their nation. This implies that positive views surpass the negative ones by approximately $60 \%$.

In question two, participants were asked to provide a precise account on views about their being Colombians. Answers to this question display that $13.3 \%$ hold slightly negative views about their identity, $6.7 \%$ hold neuter views about it, $13.3 \%$ hold slightly positive views in terms of their identity, $40 \%$ positive perceptions about being Colombians, and $26.7 \%$ hold very positive views about themselves as Colombians. Adding positive percentages, we find that $73.3 \%$ of participants have positive impressions about their being Colombians, contrasted to a low $6.7 \%$ who hold a negative impression about themselves as Colombian citizens. This means that positive views exceed the negative perceptions by $66.6 \%$.

In question three, student-teachers were prompted to give an accurate account on their views about Colombians in general. $6.7 \%$ hold slightly negative views about Colombians' identity, $13.3 \%$ have negative views about their co-nationals, $6.7 \%$ have neuter views about Colombians, $20 \%$ hold slightly positive views about their fellow-citizens, $26.7 \%$ have positive views about their compatriots, and the remaining $26.7 \%$ hold very positive views about their co-nationals. If we add positive percentages, we find that $73.4 \%$ of participants have positive 
perceptions about their compatriots, contrasted to the $20 \%$ who have negative views about their co-nationals. This indicates that positive views surpass the negative ones by $53.4 \%$.

In question 4, student-teachers were instructed to choose among a list of positive and negative choices, the ones they felt represented their country. The commonest positive choices they made were typical celebrations with $80 \%$, beautiful country with $80 \%$, diversity of places with $66.7 \%$, racial diversity with $66.7 \%$, natural resources with $66.7 \%$, and coffee with $66.7 \%$. In this order of ideas, most positive choices made by participants are related to cultural aspects (typical celebrations), natural aspects (beautiful country, natural resources, and coffee), geographic aspects (diversity of places), human aspects (racial diversity), and culinary aspects (coffee).

The commonest negative choices they picked were corruption with $86.7 \%$, violence with $73.3 \%$, bad government with $66.7 \%$, poverty with $66.7 \%$, lack of opportunities with $66.7 \%$ and inner conflict with $66.7 \%$. In this vein, most negative choices picked by student-teachers are connected to political aspects (corruption, bad government), social (lack of opportunities and violence) and economic aspects (poverty).

In question 5, participants were told to choose among a list of positive and negative adjectives, the ones they sensed represented their identity as Colombians. The commonest positive choices they made were hardworking $(80 \%)$, beautiful $(60 \%)$, courageous $(53.3 \%)$, friendly $(53.3 \%)$, charismatic $(53.3 \%)$ and ingenious $(53.3 \%)$. Thus, most positive choices picked by participants are connected to adjectives implying character (hardworking, courageous, and ingenious), appearance(beautiful) and personality (friendly and charismatic).

The commonest negative choices they picked were corrupt (33.3\%), advantageous (33.3\%), selfish (26.7\%), opportunist $(26.7 \%)$, greedy $(20 \%)$ and rude (20\%). Therefore, most negative choices made by student-teachers are associated with adjectives denoting moral quality (corrupt, advantageous and opportunist) and personality (selfish, greedy, and rude). It is important to remark that adjectives referring to positive characteristics have much higher percentages than the ones indicating negative traits. This means that in terms of percentages average, views participants have on themselves as Colombians tend to be more positive than negative.

In question 6 , respondents were asked to choose among a list of positive and negative adjectives, the ones they regarded as being representative of Colombians' identity in general. The commonest positive choices they picked were hardworking (73.3\%), patriotic (66.7\%) ingenious $(60 \%)$, devoted $(60 \%)$, strong $(60 \%)$ optimistic (53.3\%), and charismatic (53.3). Consequently, most positive choices made by student-teachers are associated with adjectives making reference to character (hardworking, strong, devoted and ingenious), personality (optimistic, charismatic) and social approval (patriotic).

The commonest negative choices picked by participants were opportunist (66.7\%), advantageous (53.35), racist (46.7\%), rude (40\%), corrupt (40\%), chauvinist (40\%), unreliable (26.7\%), and unfair (26.7\%). Thus, most negative choices picked by respondents are related to adjectives implying moral quality (advantageous, opportunist, corrupt, and unfair), social approval (racist, chauvinist, and unreliable) and personality (rude).

\section{Discussion}

With respect to views on Colombia, we had hypothesised that perceptions participants might have about their nation would be more positive than negative, considering the patriotic nature Colombians are said to have. Indeed, results from first written narratives indicate that codes labelled positive significantly outnumbered the negative ones, implying that views student-teachers reveal on their country renders a high level of optimism towards Colombia. This idea is reinforced in the questionnaire results, in which the optimistic views are high, but not as high as the ones conveyed in the narratives.

The first and second coding phases of nouns and adjective-noun collocations expose an appreciation from participants for cultural celebrations such as carnivals, the natural beauty of landscapes and places as well as the abundance of natural resources this nation possesses; the geographical wonders Colombia has, being the plains or llanos a common word evoked; human aspects as the talent that makes Colombian artists and writers unique as well as aspects related to Colombians' idiosyncrasy, as their being happy and joyful despite adversities, their professing love for their country and for what they regard as being part of it together with their being kind to everyone; culinary aspects such as the deliciousness and variety of food, being ajiaco the most remarkable typical dish, being coffee not only the most recognised drink, but the most frequent positive word in all narratives. This indicates that there is an unquestionable and intrinsic connection between Colombia and coffee, which sometimes is associated with a natural produce; sometimes as a beverage but ultimately, we think of it as a cultural product, for Colombians and foreigners conceive of Colombia as the land of the softest coffee in the world, with a whole culture revolving around it. 
In opposition to that, within these narratives there is an accentuated pessimism towards two relevant aspects that directly affect Colombian society: politics and economy. Participants show their discouragement and despair about political issues as the internal conflict or war we are still facing, and the everlasting and exacerbated corruption that lingers in our political systems and institutions. It is worth pinpointing that the term corruption came to be not just the most repetitive word used within negative codes, but also the commonest within all narratives. By way of analogy, Colombia is to coffee positively speaking, as it is to corruption in terms of negative aspects. In the same vein, student-teachers denounced through narratives one economic phenomenon that is said to have marked Colombian history - drug trafficking. Drug trafficking has tainted almost all sectors of the country, and it would be an understatement to say that this is still a stigma on Colombia and for Colombians.

In the questionnaire, there seems to be a slight balance between optimism and pessimism in terms of percentages, which reveals how undivided opinions about Colombia are. As it happened in the narratives, some participants felt proud about cultural celebrations, the wide array of places to visit, natural resources, human aspects, and culinary symbols as coffee, amongst others. Similar to what happened in narratives, participants related their country to negative aspects which reflect how Colombia is full of problematics: political issues (bad government, corruption, and inner conflict) and a major economic issue (poverty). Unlike results in narratives, findings from the questionnaire unveiled the existence of social issues that were not remarked in the stories such as violence and lack of opportunities to make some progress.

Findings from second written narratives unveil that as we had estimated, the self-concept participants have about themselves as Colombians tends to be not just positive, but extremely positive. These optimistic views are confirmed in questionnaire results, in which it can be evidenced that positive views are high, but not as high as in the narratives. Also, pessimistic views tend to be lower in the narratives. When defining themselves as Colombians, barely did participants use two negative codes, which particularly referred to their physical appearance and personality, respectively.

Although there were not high-frequency words connected to views on own identity, it is important to stress out that results unfold the fact that some participants believed they were truly and genuinely Colombians, in the good sense of the word; others regarded themselves as being proud of their nation and of being citizens from this country, as it happened in first written narratives, some student-teachers remarked their being kind as a defining Colombian trait. Findings reveal as well that participants are prone to privileging their personality and mood over their character and appearance at the moment of giving a critical opinion on themselves. Once again, as it happened in the narratives, the questionnaire reveals that participants used personality adjectives to define themselves as Colombians. Unlike what happened in the stories, participants prioritised their identity to character adjectives, and related it to some appearance adjectives. Findings from the questionnaire also point out that this time, participants identified some negative traits in themselves as Colombians, particularly to moral qualities, and their personality. These negative adjectives represent fairly low percentages.

We had hypothesised that perceptions student-teachers might have about their co-nationals would tend to be negative. Yet, results from oral narratives and the questionnaire denote that as a matter of fact, optimistic views surpassed the pessimistic ones. Interestingly, optimistic views about compatriots tended to be higher in questionnaire responses than in oral narratives, and conversely, pessimistic views tend to be higher in narratives than in questionnaire answers. Besides, it is worth saying that pessimist views about citizen-fellows were much higher than the ones participants manifested having about themselves in both, the narratives, and the questionnaire.

Findings from oral narratives indicate that participants are optimistic about their co-nationals' identity in terms of their personality, their character, their moral qualities, and their appearance. Nonetheless, the only positive words that were repeated were respectful (personality) and beautiful (appearance). On the other hand, student-teachers showed their being discouraged about their compatriots' emotions or mood (sad) and their characteristics in terms of social approval (no words were repeated). By contrast, findings from the questionnaire display that student-teachers value their co-nationals' character, particularly their being hardworking, strong, devoted and ingenious; that they appreciate their compatriots' personality, especially their being optimistic and charismatic, and that they praise their fellow-citizens' sense of patriotism (social approval). Student-teachers are pessimistic about the moral quality of their compatriots because according to answers, some of them are advantageous, opportunist, corrupt, and unfair. Furthermore, they are also pessimistic about their being racist, chauvinist, and unreliable (social approval) and their being rude (personality). 
Revisiting important literature about studies approaching Colombian cultural identity, we find that most of the authors relate this concept to either strictly negative or positive aspects about Colombia and/or its citizens, as is the case of Motta (2015), whose findings remark cultural issues associated to the lack of appreciation for cultural icons and symbols, and the lack of education in cultural heritage; Bedoya, Romero \& Stiglich (2015), who emphasise that cultural identification is connected to knowledge about cultural patrimony, that is to say, the recognition and appreciation learners have for products, places, and icons from their country; Beltrán \& Vela (2017), who stress out issues in the process of identification as the lack of awareness and comprehension of student-teachers about the cultural diversity of their country; Pérez-Marín (2017) who reveals how Colombians identity at some point in history, was connected to a weak government, and to a poor country which needed the assistance from powerful countries as the United States from America, and Beltrán (2015) who found that some student-teachers did not feel that the aspects related to their own culture were not as appealing as cultural traits from English-speaking countries, when it comes to learning a foreign language. Our study, in turn, is intended to contribute to some extent, to the understanding of current Colombia and Colombians' identity from the perspectives and through the eyes of a group of young student-teachers from a public institution. The results that have emerged in our investigation, unlike the ones from other studies on the subject-matter, are not meant to be interpreted solely as being restrictively positive or negative because in our mindset and based upon results, Colombia as well as Colombians are characterised by aspects which despite being negative, are not to be excluded, denied or written off; they are part of Colombian history and culture, as it is the case of drug dealing and narcotraffic culture.

Equally, we are aware that the positive aspects that are associated to Colombia and its citizens are to be recognised, valued, and acknowledged but not maximized, aggrandized, exalted, or magnified since that could cause risky overgeneralisations which do not allow us to see the other side of history, which means here what is going in the country, and what is currently happening with Colombians. On the other hand, focusing too much on just negative aspects or exacerbating them might deprive us of looking at wonderful things a country like Colombia has as its biodiversity and natural beauty, and appreciating great traits about Colombians as their being hardworking and friendly.

In this very detailed study, quantitatively speaking we have shown a way to approach Colombia and Colombians in a balanced-out fashion. In the quest for similar studies, we did not find one in which a precise account of positive and negative current views on Colombia and Colombians was provided and illustrated. We did not find any quantitative study measuring three different variables: views on a nation, views on own-identity and views on connationals in general. Customarily, studies on Colombian Cultural identity focus on the country and/or its citizens providing data about those individuals in general terms; the difference between own-identity and connationals' identity is not emphasised.

The results obtained in this study imply that in the development of intercultural communicative competence in language student-teachers, particularly in basic courses, it is highly suggested that before approaching cultural issues from L2, teachers distil in learners a spirit of reflection upon the society they live in, and the reality that surrounds them. The understanding of local reality for prospective teachers also suggests that they recognise that those perceptions they hold about their country and citizens in general, might clash with the views that others have about these cultural phenomena. Hence, language teaching programes should foster the balanced idea that dealing with national identity should not be focused solely on the search for the aspects that bind us together, but also with those aspects which drift us away. When we are raised and taught to look up to aspects that are prearranged as positives, we might be blinded and deny the existence of issues that are happening somewhere in the country, and just because we are not facing them, it does not mean they are not factual. Conversely, if we are educated to be critical of everything, and just see the negative side of our country and co-nationals, we might deprive ourselves of enjoying the benefits that a country like Colombia offers and appreciating the great qualities Colombians are endowed with.

We acknowledge that this has been a short-scale investigation whose findings might be transferred to some educational settings, particularly to university language teaching programmess where intercultural communicative competence and citizenship competences are key in the curriculum. We also know that including a larger sample of participants would have been further revealing and enlightening. That is precisely why we are committed to complementing this study by carrying out a mixed investigation with participants from different semesters. We suggest that longitudinal studies be done in the field to find out if perceptions either positive or negative prevail or transform, and that studies sampling people from different ages and backgrounds be conducted to approach Colombian identity more profoundly. 


\section{References}

Aguaded, E. M. (2006). La educación de competencias básicas para el desarrollo de la ciudadanía intercultural en la ESO. Actas del V Congreso Internacional Educación y Sociedad: Retos del s. XXI, Universidad de Granada, p. 3.

Areizaga, E. (2001). Cultura para la formación de la competencia comunicativa intercultural: el enfoque formativo. Revista de Psicodidáctica, 12. Retrieved from https://www.redalyc.org/articulo.oa?id=17501205

Bedoya, A., Gordillo, L., Romero, L., \& Stiglich, R. (2015). Colombian Cultural Identity In The Teaching Of English As A Foreign Language. Opening Writing Doors Journal, 12(1). Retrieved from https://revistas.unipamplona.edu.co/ojs_viceinves/index.php/OWD/article/view/1640

Beltrán, L. (2015). Influencia cultural en la motivación para el aprendizaje del inglés como lengua extranjera. RIIEP, 8(2), 341-371. https://doi.org/10.15332/s1657-107X.2015.0002.07

Beltrán, L., \& Vela, W. (2017). An EFL Teacher Candidates Teaching Experience from Action Research and Intercultural Communicative Competence. Revista Papeles, 9(17), 79-86. https://doi.org/10.54104/papeles.v9n17.471

Bhabha, Homi K. (2007). El lugar de la cultura. - 1a ed. 1a reimp. Manantial.

Burkholder, G. J., Cox, K. A., Crawford, L. M., \& Hitchcock, J. H. (Eds.). (2019). Research Design and Methods: An Applied Guide for the Scholar-Practitioner. SAGE Publications, Incorporated.

Byram, M. (1997). Teaching and Assessing Intercultural Communicative Competence. Multilingual Matters.

Chen, T. (2020). La diferencia entre la competencia comunicativa y la competencia intercultural en la enseñanza/aprendizaje de lenguas extranjeras. Confuci Acadèmic Journal, 1, 85-94. Retrieved from https://confuciobarcelona.es/journal/wp-content/uploads/2020/09/caj2020_chen.pdf

Chen, V. H. H. (2014). Cultural identity. Key Concepts in Intercultural Dialogue, 22. Retrieved from https://centerf\&orinterculturaldialogue.files.wordpress.com/2014/07/key-concept-cultural-identity.pdf

Gholaminejad, R. (2017). Identity Construction and Reversal Conceptual Transfer Among Iranian EFL Learners. How Journal, 24(2), 63-79. https://doi.org/10.19183/how.24.2.341

Hall, S., \& Du Gay, P. (Eds.). (1996). Questions of cultural identity. Sage Publications, Inc.

Meihami, H., \& Salite, I. (2019). EFL Teachers' Cultural Identity Development through Participating in Cultural Negotiation: Probing EFL Students Perspectives. Journal of Teacher Education for Sustainability, 21(1), 115-127. https://doi.org/10.2478/jtes-2019-0009

Motta, G. (2015). Una mirada a través del arte: vinculación del pasado y el presente del patrimonio cultural colombiano en la educación [Tesis de doctorado, Universidad Complutense de Madrid]. Retrieved from https://eprints.ucm.es/id/eprint/34336/1/T36692.pdf

Oprescu, M. (2016). Culture and Identity in EFL Contexts. In Beliefs and Behaviours in Education and Culture: Cultural Determinants and Education (ed.). Retrieved from https://www.researchgate.net/publication/321706835_Culture_and_Identity_in_EFL_Contexts

Pérez-Marín, M. (2017). Critical Analysis of the Identity Discourse of Colombians in the National Geographic Magazine (1903-1926). Signo pensam, 36(71), 136-154.

Vélez, F. (2019). La Construcción de la Identidad Cultural en el Currículum de Ciencias Sociales Un Estudio de Caso en un IES de Algeciras [Tesis de doctorado, Universidad de Cádiz]. Retrieved from https://www.researchgate.net/publication/338230340_La_construccion_de_la_identidad_cultural_en_el_cur riculum_de_Ciencias_Sociales_Un_estudio_de_caso_en_un_IES_de_Algeciras

\section{Copyrights}

Copyright for this article is retained by the author(s), with first publication rights granted to the journal.

This is an open-access article distributed under the terms and conditions of the Creative Commons Attribution license (http://creativecommons.org/licenses/by/4.0/). 